\title{
EL RETORNO DE LA IZQUIERDA EN SUECIA
}

Superando ampliamente las previsiones, el «bloque socialista» ha alcanzado mayoría absoluta en las elecciones celebradas el día 19 de septiembre de 1982 en Suecia.

En efecto, el bloque socialista, formado por el Partido Socialdemócrata y el Partido Comunista, consiguió 186 diputados frente a los 163 del «bloque burgués», compuesto por el Partido Conservador, el Liberal y el de Centro.

Durante la campaña electoral, los electores suecos han hecho abstracción del negro panorama preconizado por los partidos del «bloque burgués» en el caso de producirse, como ha ocurrido, un triunfo de la izquierda - sobre todo, en lo relacionado con la idea de la creación de un «fondo de asalariados»-. El ciudadano medio sueco ha hecho balance de los seis años de «poder burgués», ha comprobado que el paro se ha triplicado en ese período, llegando a ser ya preocupante entre las mujeres y los jóvenes; ha visto aumentar el déficit presupuestario y el monto de la deuda pública $y$, además, se ha visto amenazado con recortes en la Seguridad Social. El balance, pues, no podría resultar más que negativo para el «bloque burgués», sabre todo porque, desde la izquierda, el Partido Socialdemócrata, aun mostrándose cauteloso en sus ofrecimientos preelectorales, presentaba a los suecos: un plan de lucha solidaria contra el paro, ideas concretas para el relanzamiento de la industria, retorno de Suecia al campo de la neutralidad y, en definitiva, una vida mejor.

Los resultados electorales fueron los siguientes:

\section{CuAdro 1}

VOTOS, PORCENTAJES Y ESCANOS TRAS ĖL 19 DE SEPTIEMBRE DE 1982

\begin{tabular}{|c|c|c|c|c|c|c|}
\hline \multirow[t]{2}{*}{. } & \multicolumn{3}{|c|}{. 1982} & \multicolumn{3}{|c|}{.1979} \\
\hline & Votos & $\%$ & Escaños & Votos & $\%$ & Escaños \\
\hline BLOQUE BURGUÉS: & & $\ddots$ & & . & & \\
\hline $\begin{array}{l}\text { Partido Conservador } \\
\text { (Moderata Samlingspartiet) ... }\end{array}$ & 1.290 .091 & 23,6 & 86 & 1.108 .406 & 20,3 & 73 \\
\hline $\begin{array}{l}\text { Partido Centrista } \\
\text { (Centerpartiet) } \ldots \\
\text { (C. }\end{array}$ & 849.385 & 15,5 & 56 & 984.589 & 18,1 . & .64 \\
\hline $\begin{array}{l}\text { Partido Liberal } \\
\text { (Folkpartiet) } \ldots \ldots \ldots \\
\text { Fo . . . . . . }\end{array}$ & 322.747 & 5,9 & 21 & 577.063 & 10,6 & 38 \\
\hline TOTAL BLOQUE BURGUÉs ... & $2.462 .223^{\circ}$ & 45,0 & 163 & 2.670 .058 & 49,0 & 175 \\
\hline
\end{tabular}

Revista de Derecho Politico

Núm. 16. Invierno 1982-1983 


\begin{tabular}{|c|c|c|c|c|c|c|}
\hline & \multicolumn{3}{|c|}{1982} & \multicolumn{3}{|c|}{1979} \\
\hline & Votos & $\%$ & Escaños & Votos & $\%$ & Escaños \\
\hline \multicolumn{7}{|l|}{ BLOQUE SOCIALISTA: } \\
\hline $\begin{array}{l}\text { Partido Socialdemócrata (So- } \\
\text { cialdemoktatiska } \\
\text { partiet) }\end{array}$ & 2.507 .169 & 45,9 & 166 & 2.356 .234 & 43,2 & 154 \\
\hline $\begin{array}{l}\text { Partido Comunista (Vänster- } \\
\text { partiet kommunisterna) ... }\end{array}$ & 303.581 & 5,6 & 20 & 305.420 & 5,6 & 20 \\
\hline TOTAL BLOQUE SOCIALISTA ... & 2.810 .750 & 51,5 & 186 & 2.661 .654 & 48,8 & 174 \\
\hline
\end{tabular}

Fuente: Embajada de Suecia en Madrid.

\section{Cudaro 2}

PORCENTAJES ELECTORALES DE LOS PARTIDOS SUECOS DESDE 1932

\begin{tabular}{|c|c|c|c|c|c|c|}
\hline Año & $\begin{array}{l}\text { Conserva- } \\
\text { dores }\end{array}$ & Liberales & Centristas & $\begin{array}{c}\text { Social- } \\
\text { demócratas }\end{array}$ & Comunistas & Otros \\
\hline $\begin{array}{llll}1932 & \ldots & \ldots & \ldots \\
1940 & \ldots & \ldots & \ldots \\
1948 & \ldots & \ldots & \ldots \\
1956 & \ldots & \ldots & \ldots \\
1958 & \ldots & \ldots & \ldots \\
1964 & \ldots & \ldots & \ldots \\
1968 & \ldots & \ldots & \ldots \\
1970 & \ldots & \ldots & \ldots \\
1973 & \ldots & \ldots & \ldots \\
1976 & \ldots & \ldots & \ldots \\
1979 & \ldots & \ldots & \ldots\end{array}$ & $\begin{array}{l}23,1 \\
18,0 \\
12,3 \\
17,1 \\
19,5 \\
13,7 \\
12,9 \\
11,5 \\
14,3 \\
15,6 \\
20,3\end{array}$ & $\begin{array}{r}12,2 \\
12,0 \\
22,8 \\
23,8 \\
18,2 \\
17,0 \\
14,3 \\
16,2 \\
9,4 \\
11,1 \\
10,6\end{array}$ & $\begin{array}{r}14,1 \\
12,0 \\
12,4 \\
9,4 \\
12,7 \\
13,2 \\
15,7 \\
19,9 \\
25,1 \\
24,1 \\
18,1\end{array}$ & $\begin{array}{l}41,7 \\
53,8 \\
46,1 \\
44,6 \\
46,2 \\
47,3 \\
50,1 \\
45,3 \\
43,5 \\
42,7 \\
43,2\end{array}$ & $\begin{array}{l}8,3 \\
4,2 \\
6,3 \\
5,0 \\
3,2 \\
5,2 \\
3,0 \\
4,8 \\
5,3 \\
4,8 \\
5,6\end{array}$ & $\begin{array}{l}3,6 \\
4,1 \\
2,3 \\
2,4 \\
1,7 \\
2,1\end{array}$ \\
\hline
\end{tabular}

1 Estas elecciones, celebradas en plena guerra, fueron consideradas como un voto de confianza al primer ministro socialdemócrata.

2 Elecciones extraordinarlas por la controversia sobre pensiones suplementarias, una vez disuelto el Parlamento.

FuENTE: Embajada de Suecia en Madrid.

En cuanto al «bloque burgués», el Partido Conservador es el único de sus componentes que ha conseguido mantener e incluso superar sus anteriores porcentajes. El 23,6 por 100 alcanzado constituye el mejor resultado electoral conservador desde el año 1932. El Partido Liberal, en cambio, al recoger el 5,9 por 100 de los sufragios sufre su mayor descalabro electoral desde el mismo año (Cuadro 2).

Por lo que se refiere al «bloque socialista», resalta en primer lugar el dato de que el Partido Socialdemócrata supera, por sí solo - sin necesidad de tecurrir al apoyo de los escaños comunistas-, el número de diputados conseguidos por los «partidos burgueses».

El Partido Comunista, en lo que ha sido considerado como un éxito electoral, logra mantener su número de representantes en el Riksdag (20) y pierde la insignificante cantidad de 1.839 votos con respecto a las elecciones de 1979 . 


\section{LOS PARTIDOS SUECOS}

La historia política reciente de esta monarquía parlamentaria nórdica está protagonizada por el Partido Socialdemócrata, pues no en vano consiguió mantenerse ininterrumpidamente en el poder desde 1932 hasta 1976. El Partido Socialdemócrata es, sin duda, la formación política sueca que agrupa al mayor número de militantes al igual que de votantes. Desde 1933 a 1936 los socialdemócratas llegaron a un acuerdo de cooperación parlamentaria con el Partido Centrista, y durante los períodos de 1936 a 1939 y de 1951 a 1957 ambas formaciones gobernaron en coalición. En el resto de las legislaturas hasta 1976, el Partido Socialdemócrata ocupó el ejecutivo en solitario. La socialdemocracia sueca está íntimamente ligada al movimiento sindical obrero, muchos dirigentes de L. O. ${ }^{1}$ son diputados en el Riksdag por el Partido Socialdemócrata. Desde el año 1970, Olof Palme es el líder indiscutible de los socialdemócratas suecos.

El Partido Comunista nace como resultado de una escisión del Partido Socialdemócrata en 1917. Sus relaciones con el Partido Comunista de la Unión Soviética nunca fueron extraordinarias y las controversias constantes entre prosoviéticos y antisoviéticos provocaron varias escisiones en su seno a lo largo de su historia. En los años sesenta el Partido Comunista sueco rompe sus lazos con la Unión Soviética.

En las elecciones de 1976 los partidos de centro-derecha alcanzaron la mayoría absoluta (180 escaños). Se ponía fin de esta manera a una larga permanencia en el poder del Partido Socialdemócrata, que durante cuarenta y cuatro años ejerció en solitario el poder ejecutivo o formó parte de él en coalición con otras fuerzas.

El «bloque burgués», integrado por los partidos de centro-derecha, está formado por el Partido Conservador, el Partido Liberal y el Partido Centrista. El primero de ellos, de ideología moderadamente conservadora, es el partido más empeñado en la construcción de un sólido «bloque no socialista». En 1969 cambió su nombre por el de Partido de Unión Moderado. En las elecciones de 1979 se convirtió en la más importante fuerza burguesa, papel que sigue desempeñando en la actualidad. El Partido Liberal ha ido acusando una tendencia a la baja desde las elecciones extraordinarias de 1958, situándose porcentualmente, tras estas últimas elecciones de 1982, muy cerca del 5,6 por 100 alcanzado por el Partido Comunista y, por consiguiente, peligrosamente próximo al mínimo 4 por 100 exigido para alcanzar representación parlamentaria. El Partido Centrista debe su actual denominación a la reorientación política iniciada en el seno de la antigua Alianza de Agricultores - organización para la defensa de los intereses agrarios y de la población rurala mediados de la década de los cincuenta, de cara al intento de representar a otras capas sociales además de Ias rurales. Formó coalición con el Partido Socialdemócrata - como ya he mencionado anteriormente- en dos períodos: de 1936 a 1939 y de 1951 a 1957.

Suecia es una monarquía parlamentaria en base a la Constitución del 6 de junio de 1809. El Gobierno es responsable ante el Parlamento (Riksdag) unicameral. El sistema bicameral fue abolido por una enmienda constitucional de 1968-1969. Este sistema había estado vigente desde 1866. En 1971 fue constituido el primer Riksdag unicameral. Este ejerce la función legislativa y está compuesto por 349 diputados que son renovados por sufragio universal directo cada tres años. En las elecciones tienen derecho a participar todos los suecos mayores de dieciocho años. Los miembros del Riksdag son elegidos en base al sistema de representación proporcional. El mínimo exigible a cada partido para alcanzar representación parlamentaria es del 4 por 100 de los sufragios, si bien basta que una formación política alcance el 12 por 100 de votos en un solo distrito electoral para conseguir un escaño. El Riksdag tiene un presidente (Talman) y tres vicepresidentes.

1 Unión General de Trabajadores de Suecia.

Fernando Ollero Butler 